\title{
Hacia una "transición modelo": influencia y significación de la transición española en la oposición chilena a la dictadura (1980- 1987) ${ }^{*}$
}

\section{Towards a "transitional model" influence and significance of the Spanish transition in opposition to the Chilean dictatorship (1980-1987)}

Patricio Ruiz Godoy**

\begin{abstract}
Resumen
El presente texto analiza la recepción y significación de la transición española en la oposición política a la dictadura de Augusto Pinochet. Específicamente, desde la llamada "historia transnacional", determinaremos el grado de influencia que tuvo el proceso español en la formación y consolidación de una oposición política durante la década de los ochenta. El artículo sostiene que existió una utilización de la experiencia ibérica y su noción de "transición modelo" como forma de legitimar el tipo de transición propuesto por algunos sectores opositores representados en la "Alianza Democrática", especialmente en lo relativo a dos conceptos claves: 1) "consenso social", referido a la unidad de los partidos "democráticos" y la necesidad de llegar a ciertos acuerdos con la dictadura y 2) "ruptura pactada", entendida como la aceptación de la legalidad pinochetista.
\end{abstract}

Palabras claves: Historia transnacional-Transición-Chile-España-ruptura pactada

\begin{abstract}
This paper analyzes the reception and significance of the Spanish transition in political opposition to the dictatorship of Augusto Pinochet. Specifically, from the "transnational history", will determine the degree of influence that had the Spanish process in the formation and consolidation of political opposition during the eighties. This article argues that there was a use of the Iberian experience and his notion of "transition model" as a way of legitimizing the transition type proposed by some opposition groups represented in the "Alianza Democrática", especially with regard to two key concepts: 1) "social

\footnotetext{
* El presente artículo se realizó en el contexto de la elaboración de la tesis para optar al grado de Magíster en Historia en la Universidad de Santiago, centrada en el debate sobre la transición chilena durante la década del ochenta a través del estudio del conglomerado político denominado "Alianza Democrática". Agradezco los comentarios realizados por la Doctora en Historia Cristina Luz García y los licenciados en Historia Jessabel Guamán Flores, Paola Jaña Contreras y David Coronado Canales.

${ }^{* *}$ Licenciado en Historia, Universidad de Concepción. Tesista Magíster en Historia, mención Historia de Chile, Universidad de Santiago.
} 
consensus", based on the unity of the "democratic" parties and the need of reach certain agreements with the dictatorship and 2) "negotiated rupture", understood as the acceptance of the Pinochet legality.

Keywords: Transnational history-Transition-Chile-Spain-Negotiated rupture

La transición chilena y sus protagonistas políticos ha sido un tema poco abordado por la historiografía nacional. Luego del boom transitológico de los setenta y ochenta ${ }^{1}$, esta temática fue dejada de lado por las ciencias sociales, enfocándose en otros procesos. Se suponía que después de ocurrida la transición, serían los historiadores quienes se encargarían de estudiar este proceso, lo cual aún no ocurre salvo excepciones ${ }^{2}$. La cercanía en el tiempo, la falta de consenso en la determinación de sus "márgenes" cronológicos o el enfoque en otros actores "secundarios" del periodo ${ }^{3}$ pueden ser aducidos como las razones para esta aparente omisión.

Tomando lo anterior en cuenta, en el presente artículo pretendemos aportar al estudio historiográfico de la transición chilena utilizando la perspectiva de la historia transnacional. Para esto, nos centraremos en la conformación de la oposición política a la dictadura de Pinochet durante la década de los ochenta, especialmente en aquellos sectores más moderados que dieron vida a la denominada "Alianza Democrática". Creemos que estos sectores formaron una verdadera cultura política de "transición" durante estos años, la cual se basaría en la resignificación de ciertos conceptos claves para el propio proceso transicional, como las nociones de "consenso", "concertación social" o "ruptura pactada". Durante la misma época, España comenzaba a afianzar su democracia luego de la muerte de Franco en 1975. Tempranamente se comenzó a observar a la transición española como un "modelo" para el resto de los países, pues esta habría sido pionera en la realización de un proceso pacífico y consensuado entre todos los sectores políticos ${ }^{4}$. El propio Estado español habría aprovechado esta coyuntura para afianzar la "marca España" en el mundo, proyectando la imagen de un país serio y renovado que se abría a Europa y al resto del orbe (García Gutiérrez, 2013). De esta forma, develaremos el cruce que existió entre ambos procesos, especialmente en lo relativo a la influencia que ejerció el imaginario de la transición española en la oposición chilena. Nuestra hipótesis es que uno de los aspectos de los cuales se alimentó semánticamente la nueva cultura política chilena fue la observación de otros procesos de transición y las "lecciones" que de estos se podían extraer. En este sentido, el caso español es paradigmático, pues calzaba a la perfección con el cariz que iba

\footnotetext{
${ }^{1}$ Desde la llamada "transitología” existe un nutrido cuerpo de investigaciones que describen la transición chilena desde una óptica estructuralista. Un buen resumen de estas hipótesis se encuentra en Cañas (1997)

${ }^{2} \mathrm{Si}$ bien no existe alguna obra historiográfica que aborde este proceso de forma general, algunas obras que lo abordan parcialmente son Yocelevsky (2002), Portales (2000) y Goicovic (2006).

${ }^{3}$ Llama la atención el auge que ha tenido el estudio de algunos grupos políticos que si bien fueron relativamente pequeños, generan un gran interés de la historiografía nacional, como son los casos del Movimiento de Izquierda Revolucionario (MIR) y el Frente Patriótico Manuel Rodríguez.

4 Esta interpretación edulcorada de la transición española ha comenzado a ser cuestionada desde la historiografía y otras ciencias sociales, develando ciertos aspectos invisibilizados del proceso, como la violencia política o el papel de la sociedad civil. Un par de ejemplos son González (2008) y Sánchez-Soler (2010).
} 
adquiriendo la transición chilena a medida que avanzaban los años ochenta: las nociones de unidad entre el centro y la izquierda renovada (representadas por la Democracia Cristiana y los sectores renovados del Partido Socialista) y la idea de una transición pactada, que aceptaba tácitamente la institucionalidad establecida en la Constitución de 1980.

Por otra parte, creemos que la perspectiva transnacional nos permite entregar nuevas luces al proceso histórico de la transición a la democracia (Pedrosa, 2013). Los primeros estudios históricos que integraron esta variable fueron de carácter cultural, vinculados a las corrientes postcoloniales de estudio ${ }^{5}$. Estos autores entendían que el concepto de estadonación no podía ser una cortapisa a la hora de analizar procesos históricos más amplios, que respondían a lógicas de intercambios culturales mutuos entre la metrópolis y sus colonias (García Gutiérrez, 2010). Posteriormente, la historiografía en general comenzó a integrar este enfoque, practicando una suerte de revisionismo al repensar ciertos procesos históricos a través de esta perspectiva (De la Guardia y Pan-Montojo, 1998). La existencia de procesos que superan el ámbito de lo nacional y se extienden por más de un país, zona geográfica o continente es una realidad a la cual la historiografía no ha podido quedar ajena, y que ha sido reconocido en los últimos tiempos, especialmente en los estudios sobre historia del tiempo presente, donde el fenómeno de la globalización ha potenciado de forma exponencial su existencia

En el caso chileno, existen algunos historiadores que han introducido conceptos transnacionales en sus investigaciones, las cuales, en general, se han relacionado con la historia política de Chile durante el siglo XX, especialmente en temáticas derivadas de la llamada "Guerra Fría Global"6, superando las estrechas barreras impuestas por los límites geográficos nacionales y un aparente nacionalismo que se encontraba implícito en los estudios históricos chilenos (Fermandois, 2009).

El marco cronológico de este estudio se extiende desde 1980, donde a raíz del plebiscito para aprobar la nueva Constitución, la oposición comienza a encontrar los primeros espacios de discusión en el debate público luego del golpe (proceso que se aceleraría en 1983) hasta 1987, año en que se disolvió la Alianza Democrática y la aceptación del plebiscito de 1988 determinó el éxito de la opción de "ruptura pactada" dentro de la oposición política a la dictadura cívico-militar. Las fuentes utilizadas fueron principalmente los medios escritos proclives a la oposición (las llamadas "revistas de oposición"), junto a una serie de documentos y bibliografía secundaria, lo cual nos permite seguir la trayectoria de estos sectores y las formas en que se relacionaron con el mundo hispano.

Chile y España: dos casos de transiciones pactadas

\footnotetext{
${ }^{5}$ Destacan los trabajos de Edward Said y Franz Fanon.

${ }^{6}$ Algunos autores destacados son Joaquín Fermandois, Fernando Purcell y Olga Ulianova, entre otros.
} 
Si bien el objetivo de este artículo no es realizar un ejercicio de historia comparada entre los procesos transicionales de Chile y España ${ }^{7}$, es necesaria una sucinta contextualización de ambos fenómenos. En primer lugar, describiremos el caso ibérico, con el objetivo de comprender la formación del "modelo español" de transición y su proyección internacional. Luego, esbozaremos algunas ideas sobre la transición chilena, buscando ciertas similitudes y diferencias al caso antes descrito. Todo esto con el objeto de contextualizar el proceso de agrupación de la oposición chilena y su relación con la transición española.

A diferencia del caso chileno, en España existe un consenso relativamente generalizado sobre los límites cronológicos de la transición. Esta habría comenzado en 1975 con la muerte del dictador Franco y culminaría en 1982 con la asunción a la primera magistratura de Felipe González y el Partido Socialista Obrero Español (PSOE). El régimen de Franco pasó por varios periodos, desde un breve periodo corporativista hasta una institucionalización autoritaria basado en un apoliticismo social y el papel de Franco como árbitro entre las distintas "familias" que convivían dentro de la estructura de poder (Sánchez Recio, 1994). Si bien se ha discutido latamente la verdadera naturaleza del franquismo, se ha impuesto la tesis sobre su impronta autoritaria, donde se ejercía un férreo control desde el Estado pero sin llegar a inmiscuirse en todos los ámbitos de la población ${ }^{8}$. Otro aspecto importante del régimen franquista que influyó en el tipo de transición acaecido fue la economía. Recién instaurado el caudillo en el poder, implementó una economía autárquica, gracias al aislamiento internacional producido luego de la victoria de los aliados en la Segunda Guerra Mundial. Ya en la década de los 50, en plena Guerra Fría, la importancia geopolítica de España la acerca a Estados Unidos y el resto de Europa (Rodríguez, 2014). Este nuevo acercamiento entre ambos países terminó con el aislamiento internacional del régimen y favoreció una paulatina apertura de la economía nacional, aunque aún era muy inferior a la de otros países del continente, como Alemania o Francia.

A mediados de los sesenta comenzó un auge económico que mejoró de forma notable, aunque desigual, el nivel de vida de la mayoría de la población, formando una clase media pujante. Pero entrado los setentas, esta realidad comenzó a cambiar. El modelo económico mostraba algunas fisuras y el ascenso de la clase media (nacida al alero del propio boom) demostró una creciente desafección a un régimen que se eternizaba en el poder (Saz, 2011). Todo este descontento - sumado a una cierta reorganización de las fuerzas políticas opositoras- tuvo su catalizador en la muerte del dictador el 20 de noviembre de 1975, dando comienzo al proceso transicional. Luego de este suceso, el poder queda en manos del Consejo de Regencia, el cual asume las funciones de la Jefatura del Estado hasta el 22 de noviembre, fecha en la que fue proclamado rey ante las Cortes y el Consejo del Reino Juan Carlos I de Borbón, el cual ya había sido ungido por el

\footnotetext{
${ }^{7}$ Existen estudios realizados desde una perspectiva comparada entre ambos procesos, especialmente desde la "transitología", como por ejemplo Alcántara (1992).

${ }^{8}$ Sobre la discusión por la "naturaleza" del régimen franquista, revisar Guillermo Olmo e Israel Viana, "¿Totalitario o autoritario? Franco fue por encima de todo un superviviente", Diario ABC (Madrid), 9 de diciembre de 2013, asequible de forma digital en http://www.abc.es/20110604/archivo/abci-totalitarioautoritario-franco-sobre-201106030839.html
} 
mismísimo Franco como sucesor en 1969, proclamando en España la que, se supone, era su forma histórica de gobierno: la monarquía.

Juan Carlos mantiene en el poder al primer ministro franquista, Carlos Arias Navarro. Sin embargo, la negativa de este a realizar ciertas reformas hizo que el rey le exigiera su renuncia. Su sustituto fue el franquista moderado Adolfo Suárez, quien se encargaría de negociar con la oposición y comenzar un proceso de democratización. La vía utilizada para esto fue la elaboración de una nueva Ley Fundamental (la octava), la que no sin tensiones fue finalmente aprobada por las Cortes franquistas y sometida a referéndum el día 15 de diciembre de 1976 y promulgada el 4 de enero de 1977. Este nuevo ordenamiento se aleja en gran medida del legado franquista en apenas cinco artículos y estableció el llamado a elecciones democráticas. La Unión de Centro Democrático (UCD) de Adolfo Suarez obtenía el triunfo y conformaba el gobierno, produciendo en este periodo el proceso constituyente que finalmente daría vida a una nueva Constitución. Este proceso se realizó en una comisión parlamentaria y no en una Asamblea Constituyente, delineando lo que sería el "modelo español" de transición, basado en un pacto entre todas las fuerzas políticas (incluidas las de pasado franquista) y realizado entre cúpulas partidistas. En 1981 dimite Suarez, y una vez superado un intento de golpe de Estado, el PSOE sucede a la UCD tras obtener la mayoría absoluta en las elecciones generales del 82, comenzando así la Segunda Legislatura de España. Este hecho marcaría el fin de la transición española e inmortalizaría el mito de la "modelo español", el cual ciertamente oscurece muchos aspectos propios del periodo, como la violencia de Estado y la movilización social (Ortiz Heras, 2004; Mir García, 2007)

En Chile, el proceso transicional aún no ha sido definido con claridad. Sin embargo, como forma de contexto operacional, podemos decir que la dictadura de Augusto Pinochet puede ser dividida en dos periodos: por un parte, existe un primer momento que va desde el mismo golpe de Estado de 1973 y que se extiende hasta 1983. Este se caracteriza por la férrea represión a los partidos políticos y el carácter refundacional del régimen luego de un proceso de "estabilización". En 1980 Pinochet busca institucionalizar su "revolución" con la promulgación de una nueva Constitución que finalmente es aprobada en dudosas circunstancias. Este proceso marcaría el lento proceso de acercamiento y reorganización de las fuerzas políticas opositoras, definiendo lo que sería el periodo posterior de transición. Este segundo periodo (1983-1989) comienza con un cierto "despertar" de la sociedad civil en una serie de movilizaciones (las llamadas "Jornadas Nacionales de Protesta") que obligaron al régimen a una tibia apertura, representada en la designación de Sergio Onofre Jarpa en el Ministerio del Interior, el cual comenzó un diálogo con las fuerzas políticas ${ }^{9}$.

La oposición chilena se dividió en dos grupos, la Alianza Democrática (AD) y el Movimiento Popular Democrático (MDP). El primero fue liderado por la Democracia Cristiana y sectores del socialismo renovado junto a otros grupos pequeños, mientras el segundo agrupó al Partido Comunista y el socialismo más ortodoxo (ejemplificado en la figura del ex ministro de Allende, Clodomiro Almeyda). La diferencia entre ambos conglomerados radicaba en la validación de la acción directa como forma de oposición al

\footnotetext{
${ }^{9}$ Para una propuesta de periodización del proceso, revisar Cañas Kirby $(1994 ; 22)$
} 
régimen, aunque lo cierto es que tanto la influencia de Estados Unidos ${ }^{10}$ como la estrategia deliberada de Pinochet hacían que fuese imposible un acercamiento entre la AD y el PC. En este contexto, mientras el MDP siguió con una estrategia de movilización social, la AD optó por negociar con el régimen con el fin de adelantar el proceso transicional establecido en la Constitución del ochenta, es decir, la realización de un plebiscito en 1988 que determinaría el llamado a elecciones libres o la continuidad de Pinochet durante ocho años más. Pero la negativa del propio Pinochet a dejar el poder, junto al aumento de la represión a través de los estados de sitio, fue dinamitando esta opción, permitiendo que cada vez más sectores de la oposición comenzaran a resignarse a acatar la institucionalidad dictatorial. Si bien existió un último esfuerzo de acelerar el proceso en 1985 a través del llamado "Acuerdo Nacional" propuesto por el Cardenal Fresno, lo cierto es que la transición chilena quedó definida por su carácter transaccional, donde se aceptó mantener la Constitución del ochenta y el modelo económico, generando los llamados "enclaves autoritarios" que definirían los próximos treinta años de democracia chilena (Moulian, 1997). La expresión fáctica de esta aceptación es la formación de la Concertación de Partidos por el No en 1987 (luego de la disolución de AD), la cual se planteaba como objetivo el plebiscito de 1988, legitimando el proceso de transición pactada chilena.

Del "camino propio" al consenso democrático: imaginario del proceso español en la oposición chilena

Como ya expresamos, la década del setenta fue un periodo caracterizado por la fuerte represión ejercida por la dictadura hacia los partidos políticos y el casi inexistente debate público. La mayoría de los grupos organizados de izquierda se mantenían en la clandestinidad, luchando por la sobrevivencia, mientras la DC transitaba desde la "independencia crítica" hacia la franca oposición a la dictadura, debilitando aún más sus estructuras partidarias. Debemos recordar que en los estertores de este decenio, la dictadura comenzó a cristalizar su proyecto, tanto en el terreno económico como en el político, lo que significó el punto más bajo en las relaciones entre los partidos políticos y su antigua base social (Huneeus, 2005). Este proceso afectó más, obviamente, a las organizaciones de la oposición, que ahora incluían a la DC. No obstante, este aparente quiebre de las estructuras políticas no hizo mella en todos los partidos por igual. Lo que para la Falange fue una separación de su clientela, para la izquierda fue una verdadera destrucción de su capital social a través de la represión y el terror ${ }^{11}$. La composición más homogénea de la militancia falangista y su unidad constituida alrededor de intereses políticos, preservaron su organización aun cuando esta estuviese aislada de los sectores a lo que representaba o

\footnotetext{
${ }^{10}$ La llegada del demócrata Jimmy Carter a la Presidencia de EE.UU. supuso un cambio en las relaciones entre este país y la dictadura, sobre todo en lo relativo a los Derechos Humanos y el asesinato de Orlando Letelier en Washington. Si bien este proceso fue, en parte, revertido por Ronald Reagan (1981-1989), en 1986 las relaciones se vuelven a deteriorar y EE.UU boga fuertemente por una transición pacífica a la democracia.

${ }^{11}$ Como ejemplo, revisar el caso del Partido Comunista en Álvarez (2003).
} 
buscase representar (Yocelevsky, 2002: 186). Esto explica, en parte, el activo papel que desarrolló la DC como eje articulador de la oposición en la década siguiente.

Un producto relevante del proceso de desarticulación que sufrieron los partidos chilenos en el interior fue la autonomía adquirida por la intelectualidad con respecto a sus orgánicas partidarias. Este proceso produjo un acercamiento ideológico donde los cuadros de la izquierda provenientes de la antigua elite política confluyeron con los democratacristianos que se habían mantenido en esta actividad de forma prácticamente ininterrumpida desde el 11 de septiembre de 1973 (Yocelevsky, 2002: 194). Fueron las elites intelectuales quienes primero comenzaron un acercamiento entre el centro y la izquierda, proceso que se vio acelerado con el proyecto de nueva Constitución que proponía la dictadura, el cual fue rápidamente entendido por la oposición como la piedra angular del proyecto autoritario. Las incipientes revistas de oposición se transformaron en uno de los reductos principales de la intelectualidad opositora, convirtiéndose en una base de apoyo fundamental durante este periodo ${ }^{12}$.

Es en este contexto que la oposición comienza a visualizar las formas que debía poseer una alianza amplia que pudiera oponerse al intento gubernamental de institucionalizar su proyecto. Así, el imaginario de la transición española fue principalmente utilizado por los intelectuales, los cuales elucubraron alrededor de las condiciones que hicieron posible un proceso de tránsito hacia la democracia en otras latitudes. Una de las primeras observaciones que estos realizaron fue la experiencia de la unidad de los partidos de centro, izquierda e incluso derecha en España, agrupados en estructuras multipartidarias, las cuales habrían sostenido ciertos mínimos denominadores, como la valoración de la democracia y la condena a las violaciones de los DD.HH. Así, desde la revista APSI, Eduardo Ortiz planteaba que:

Otra lección es la realidad de una alternativa centroizquierdista. La solución española, a diferencia de lo que se repite majaderamente en nuestro medio, no consisten en dejar a la izquierda fuera de un entendimiento entre el centro y la derecha. La fórmula, por el contrario, consiste en dar cabida en el juego político al más amplio espectro de partidos y tendencias con exclusión sólo de aquellos que se aparten por iniciativa propia del juego democrático ${ }^{13}$.

Esta de idea de unidad o "concertación social" atravesó prácticamente todo el debate político durante los ochenta, donde una y otra vez los distintos actores bogaron por la unidad de la oposición (con matices relevantes como observaremos más adelante) e incluso por un acercamiento a los sectores reformistas del propio régimen. Pero lo importante a destacar es que las primeras interpretaciones que se realizaron sobre el

\footnotetext{
${ }^{12}$ El rol de las revistas de oposición en la configuración de los liderazgos de la izquierda en Moyano (2009: 55-86)

13 "Cortes españolas: la democracia no quiere a Suarez", Revista APSI 76 (1980). 17-18. El resaltado es nuestro.
} 
proceso español apuntaron hacia la constitución de un eje centro-izquierdista que era ajeno al sistema político chileno de los últimos 20 años, lo cual significaba un cambio importante en las culturas partidarias tanto de la DC como de los partidos de izquierda (Ortega Frei, 2005). De esta forma, el PSOE español fue observado como un partido de izquierda que había sabido formular una propuesta de unidad con el centro cristiano y la izquierda comunista, aunque sin llegar a construir un proyecto político común, sino más bien un consenso alrededor de la necesidad de la recuperación democrática. Heraldo Muñoz, a la fecha militante socialista, en una columna de opinión sobre los partidos socialistas alrededor del mundo, se detenía en el caso del socialismo español y planteaba que:

(...) El PSOE propone que las fuerzas democráticas renuncien parcial y temporalmente a sus legítimas aspiraciones programáticas para lograr el objetivo común de defensa de las libertades conquistadas en los últimos cuatro años. Esta experiencia democrática ya había sido consensuada en los comienzos de la transición española, incluso antes de la muerte de Franco... ${ }^{14}$

La admiración hacia el partido socialista español se daba en el contexto del proceso de renovación que vivía el socialismo chileno en el exterior. Si bien esta es una temática cuyo desarrollo excede este artículo, es importante remarcar que la transformación ideológica de gran parte de la izquierda chilena se realizó al alero de las izquierdas europeas ${ }^{15}$. El exilio propiciado por la dictadura -junto a los lazos históricos que unían a los partidos políticos chilenos con sus contrapartes internacionales- permitió que la oposición chilena tejiese una importante red de contactos y apoyos en el exterior durante los setenta. El sistema político chileno anterior a 1973 generó partidos que, en general, seguían las corrientes ideológicas mundiales, lo cual permitió que cada conglomerado relevante (como la DC, el PS y el PC) fuese acogido por partidos "hermanos" tanto en Europa como en América Latina.

Lo anterior permitió que muchos dirigentes políticos encontrasen acogida y solidaridad en países con gobiernos ideológicamente disímiles, como fue el caso de los "socialismos reales" (especialmente en la República Democrática Alemana y la URSS) (Ulianova, 2009) y las "social-democracias" occidentales: Francia, Italia y Suecia, entre otros (Camacho, 2012). También es relevante destacar la importancia de la Internacional Socialista en la inserción de los exiliados chilenos, especialmente de algunos sectores del Partido Socialista y del Partido Radical, el cual era miembro de esta organización de raigambre social-demócrata (Pedroza, 2015) En la esfera latinoamericana, destacó la acogida cubana a los exiliados socialistas y comunistas, así como el vínculo entre los grandes partidos venezolanos (AD y Copei) con los democratacristianos nacionales.

Así, la presencia de exiliados chilenos en distintos países de Europa -los cuales muchas veces se integraron y colaboraron con las orgánicas de los países que prestaban solidaridad a la causa chilena-, significó una gran influencia ideológica. Si bien el exilio

\footnotetext{
14 "Socialismo democrático en el mundo", Revista APSI, 103, (1981) 18-22.

${ }^{15}$ Sobre la renovación socialista en Chile, revisar Durán (2001: 79-91) y Moyano (2013).
} 
chileno en España fue bastante más acotado que en las naciones europeas nombradas, también influyó en varios dirigentes políticos que luego participarían de la transición chilena, como son los casos de los democratacristianos Luis Risopatrón y Andrés Zaldívar ${ }^{16}$, así como los socialistas Ricardo Núñez ${ }^{17}$ y Erick Schnake. Este último había sido senador del PS antes de 1973 y durante su exilio en España se vinculó fuertemente con el PSOE y la figura de Felipe González. En sus memorias recordaba que:

Bien mirado, ahora, a la distancia, no hay ninguna duda que en nosotros ha influido notoriamente la presencia del PSOE y especialmente su líder, Felipe González. Nuestra reivindicación permanente, sentida y verdadera, es la democracia sin apellidos, porque entendemos, y así lo planteamos... Esto es, en el esquema de las grandes divisiones del socialismo en el mundo, tomar la opción socialdemócrata, o socialista democrática, que es lo mismo, y no cabe duda que Carlos Altamirano y los que le seguimos estamos en esa postura. (Goicovic, 2010: 300)

Schnake fue un puntal de la renovación del partido socialista chileno, pues durante la división de este en 1979, adhirió a los sectores renovados e intentó reorganizar el partido desde España ${ }^{18}$. Pero sus memorias no sólo dan cuenta de su acercamiento a la socialdemocracia, sino que también al proceso de transición española y la idea del consenso social: "Felipe tenia clarísima la visión de la caída de Pinochet: Se iba a producir según él, cuando se afianzara en plenitud la alianza socialista y democratacristianos, que atraería a radicales, liberales y gentes de centro-derecha y centro-izquierda afines a estos dos grandes partidos" (Goicovic: 301). Según el propio Schnake, la solución que proponía González para la transición chilena era replicar la experiencia de la "Platajunta" española", aunque

\footnotetext{
${ }^{16}$ Destacado dirigente de la Democracia Cristiana. Si bien apoyó el golpe en un comienzo, luego de un par de años pasó a ser parte de la oposición, siguiendo a su mentor Eduardo Frei Montalva. En ese contexto, y tras supuestas declaraciones a un diario mexicano en que cuestionaba la legitimidad de la Constitución de 1980, el Gobierno le prohibió la entrada al país, debiendo radicarse en España junto a su familia. Asumió como presidente del partido entre 1976 y 1982, regresando al país al año siguiente. En el exilio había ocupado el cargo de presidente de la Internacional Demócrata Cristiana, entre 1981 y 1986. En 1981, además, fue miembro fundador de la Fundación CIPIE, en España, ocupando el cargo de presidente. Algunos detalles de este periodo en Andrés Zaldívar, La transición inconclusa (Santiago: Editorial Los Andes, 1995).

${ }^{17}$ Al momento del triunfo de la Unidad Popular, Ricardo Núñez (PS) se desempeñaba como investigador del ILPES. Asume la dirección de Planificación en la Consejería Nacional de Desarrollo Social para el Gobierno del Presidente Salvador Allende. En 1972, es electo secretario general de la Universidad Técnica del Estado. Después del Golpe de Estado del 11 de septiembre de 1973 es detenido y exiliado en 1974, permaneciendo en la RDA y en España. En este último país establecerá fuertes lazos con el PSOE, colaborando en la campaña municipal de 1979. Vuelve a Chile en 1980 y colaboró con la facción renovada del PS, liderada por Carlos Altamirano y Carlos Briones. Mayores detalles Arancibia, Góngora y Fernández (2013)

${ }^{18}$ En 1984, Schnake estuvo 14 días clandestino en Chile, participando de un Pleno del Partido Socialista (Briones). En esta estadía brinda una entrevista al Fortín Mapocho, donde expone su visión sobre la unidad de la oposición. Revisar "Me encontré con la Patria", Fortín Mapocho, 297 (1984), 6.

${ }^{19}$ Este fue un organismo unitario de oposición al régimen dictatorial creado el 26 de marzo de 1976, fruto de la fusión de la Junta Democrática de España (establecida en 1974 por el PCE y distintas figuras vinculadas a Don Juan de Borbón, con la adhesión de CCOO, PSP, PTE, ASA e independientes) con la Plataforma de
} 
adaptada a la cultura política chilena. Esto quería decir que el eje de este conglomerado no estaría en la unión del socialismo y el comunismo marxista, sino entre el socialismo democrático (obviamente representado en el sector renovado del partido) y la Democracia Cristiana, algo que como ya expresamos, representaba una novedad en la historia chilena contemporánea.

En lo que respecta a la Democracia Cristiana, lo importante durante estos años era reconstruir una opción que se opusiese al régimen de Pinochet. Según Yocelevsky, a comienzos de los ochenta, la DC se encontraba en medio de una redefinición de su camino a seguir. Los principales ideólogos del partido comenzaba a vislumbra una cierta apertura del régimen hacia la existencia de partidos, aunque fuese de forma tácita (202). En esta coyuntura, la falange debía liderar la oposición, continuando con un rasgo distintivo de su cultura política (203). El hipotético tránsito hacia la democracia sólo sería posible en la medida que hubiese un proyecto de desarrollo nacido del consenso social. En una entrevista realizada a Edgardo Boeninger ${ }^{20}$ ante la discusión sobre la unidad de la oposición y la construcción de un proyecto alternativo al representado por los militares, este contestaba que algo de esta índole:

Debería elaborarse en el transcurso del periodo de transición para ser aplicado más integralmente a partir de la reconstitución plena de la democracia. Debería ser un proyecto nacional en el sentido de interpretar a los diferentes grupos sociales y funcionales... empresarios, trabajadores, intelectuales, etc. Todos ellos deberían reconocer en este proyecto alguna parte de sus aspiraciones, de su propia visión futura del país. A Chile lo que le hace falta es el equivalente de los Pactos de la Moncloa en España, que significaron un gran acuerdo nacional en torno a qué hacer en el país durante un periodo razonable y no solamente en un muy corto plazo. Esa es una condición de estabilidad ${ }^{21}$

Observamos como el "modelo español" es presentando por Boeninger como algo deseable, una experiencia óptima que, al menos, debe ser considerada. Su alusión a los Pactos de la Moncloa resulta interesante, pues no sólo delatan el imaginario que amplios sectores de la oposición chilena tenían sobre la transición ibérica, sino que además denota

Convergencia Democrática (establecida en 1975 por el PSOE, Movimiento Comunista, democristianos y socialdemócratas). Sus objetivos fueron la amnistía, la libertad de asociación política y la convocatoria de elecciones a Cortes Constituyentes. Luego se convertiría en la Plataforma de Organismos Democráticos, la cual negoció con el gobierno de Adolfo Suárez el contenido de la reforma política llevada a cabo por éste (Ley de Reforma Política).

${ }^{20}$ Destacado militante de la DC y quien durante estos años se desempeñaba como asesor económico en varios organismos nacionales e internacionales, como el Sistema Financiero Campesino, el Rockefeller Foundation en el Evaluation Committee of Education for Development Program y en el World Bank in Public Sector Managment, en Perú. También fue miembro fundador del Grupo de Estudios Constitucionales de Chile o "Grupo de los 24".

21 "Pacto de la Moncloa para Chile”, Revista APSI, 68 (1980) 2. El resaltado es nuestro. 
la fuerte penetración que la idea del consenso y la unidad social lograba entre la oposición política a la dictadura de Pinochet.

El debate sobre la ruptura: Chile, España y las formas de transición

En la sección anterior observamos como el "modelo español" fue utilizado por algunos intelectuales de oposición chilenos para legitimar la unidad de la oposición alrededor de la idea de democracia y transición. En este apartado nos ocuparemos del periodo 1983-1987, donde la oposición reaparece en el debate público debido a una cierta apertura de la dictadura hacia los partidos.

El impacto de la primera Jornada de Protesta Nacional del 11 de mayo de 1983 contribuyó a la adopción de una nueva estrategia por parte de Pinochet, materializada en un incipiente acercamiento a la oposición a través del recién nombrado Ministro del Interior Sergio Onofre Jarpa, un "señor político"22. Esta pequeña "primavera de Jarpa" aceleró la formación de alianzas entre los distintos partidos de oposición, constituyéndose la Alianza Democrática y el MDP. Habitualmente, los pocos trabajos referidos a este periodo plantean que las diferencias entre ambos grupos correspondían a la aceptación de la violencia como forma legítima de manifestación (punto de vista representado por el PC) (Arrate y Rojas, 2003). Si bien esto es en parte cierto, otra discusión subyacía a la oposición y se trataba sobre el tipo de transición a la democracia a la cual se debía propender. Por un lado, la mayoría (prácticamente todo el MDP y parte de la AD) argumentaban que Chile estaba en condiciones de transitar hacia una ruptura democrática, entendida como un proceso de movilización social que obliga a la apertura del régimen, mientras que los sectores más moderados proponían una "ruptura pactada", en donde se acepta la institucionalidad establecida y se negociaban ciertas reformas con los sectores "blandos" de la oficialidad. Estos últimos eran, principalmente, militantes de la Democracia Cristiana, entre los que se incluía a Patricio Aylwin. Este, en un congreso realizado en 1984, planteaba que:

En España, fueron las Cortes, constituidas bajo Franco y deseosas de conservar el régimen que éste había proyectado para después de sus días y -según sus palabras - dejado bien atado, las que, en un acto de cordura y patriotismo, aprobaron la ley de reforma política que, aprobada plebiscitariamente por el pueblo español, permitió a la Madre Patria cambiar su régimen. Es lo que se llamó ruptura pactada, que hizo posible una transición pacífica y sin quebrantos del autoritarismo franquista a la democracia. ¿Por

\footnotetext{
${ }^{22}$ Expresión utilizada por el propio Pinochet para referirse a la clase política proveniente de la democracia parlamentaria pre golpe de 1973.
} 
qué no podría, en nuestra Patria, seguirse un ejemplo semejante? ${ }^{23}$ (Aylwin, 1985)

Pero lo cierto es que durante el periodo estudiado, aún no existía unanimidad respecto al tipo de transición que Chile debería observar. Esta discusión se desarrolló de manera importante durante los años 1983 y 1984. La confrontación se produjo principalmente a nivel intelectual, dentro de las distintas organizaciones opositoras. En público se intentaba demostrar una imagen de unidad (al menos dentro de cada conglomerado), influidos por la necesidad del consenso como axioma político. Así, quienes defendían una u otra posición utilizaban distintos tipos de argumentos: la situación económica, la cultura cívica chilena o el contexto internacional. Es en este último aspecto donde volvemos a encontrar el imaginario de la transición española, aunque con distintos grados de valoración. En las actas de las reuniones del Grupo de los $24^{24}$ podemos observar esta disyuntiva de forma clara. El integrante del grupo y miembro del PC Sergio Teitelboim, estaba completamente en contra del modelo de transición española. Influido por la política comunista de defensa de todas las formas de luchas, se contraponía al concepto de ruptura pactada. Teitelboim fue enfático en criticar el dialogo entre el régimen y la Alianza Democrática. Así afirmó que:

Tiene muy claro, que en cuanto al dialogo del año pasado, hubo sectores que desilusionaron al conversar con Pinochet, al intentar una salida mediante una ruptura pactada, una salida a la española. La fuerzo de los hechos demostró que el dialogo se desgajaron sectores de la protesta incluso partidos y hubo un retraso en la lucha contra las dictaduras ${ }^{25}$.

A diferencia de los sectores que defendían la ruptura pactada, este sostenía una opinión crítica del modelo español, desconociendo el papel de la izquierda en el proceso de transición española. Otra crítica la encontramos en las palabras de otro fundador del grupo, Manuel Sanhueza (PS), ex ministro de la Unidad Popular, el cual se declaró partidario de la ruptura democrática, pues proponía la renuncia inmediata del dictador y el desconocimiento de la Constitución de 1980. El socialista argumentó la necesidad de convocar una Asamblea Constituyente y el establecimiento de un gobierno provisional que conduzca el proceso de transición. El caso español no sería aplicable a Chile, pues:

Expresa que discrepa de una ruptura pactada para Chile, no hay un poder moderador, como en España el Rey, que lo haga posible.

\footnotetext{
${ }^{23}$ El resaltado es nuestro.

${ }^{24}$ El Grupo de Estudios Constitucionales o Grupo de los 24, fue un conjunto de veinticuatro juristas y personalidades de oposición al régimen de Pinochet, formado el 21 de julio de 1978. Su objetivo fue crear un proyecto alternativo de Constitución para el país, en contraste al anteproyecto de la Constitución Política de la República de 1980, redactado por la Comisión Ortúzar, establecida en 1973 por el régimen cívico-militar de Pinochet. Las citas a continuación presentadas fueron extraídas de Araya (2012).

${ }^{25}$ Acta reunión Comisión de Estudios Constitucionales, 5 de abril de 1984, 7 en Archivo Histórico Fundación Eduardo Frei Montalva. El resaltado es nuestro.
} 
(...) No le ve el objeto al dialogo ya que estamos en posiciones irreconciliables (...) Para el dialogo no hay interlocutores válidos. ${ }^{26}$

En otras palabras, Sanhueza no descartaba de plano el modelo español, pero si lo consideraba inaplicable para el caso chileno, pues no habría un ente mediador (el rey Juan Carlos) que sirviese como bisagra para los acuerdos entre los sectores reformistas de lado y lado. También percibía que dentro de la civilidad que apoyaba a Pinochet no había alguna figura que fuese capaz de desafiar la autoridad del dictador. Y por si fuera poco, los sectores "blandos" del régimen (hablando en términos transitológicos), eran débiles y las FF.AA estaban subyugadas bajo la impronta de Pinochet. Todo esto marcaba una diferencia cualitativa con el caso español, pues la muerte de Franco habría facilitado el proceso, pues no existía figura alguna dentro del franquismo que aglutinase a las múltiples "familias" que componían el régimen del generalísimo ${ }^{27}$.

Sin embargo, dentro del Grupo de los 24 también hubo defensores del proceso español. Estos fueron los representantes de la DC, partido donde el concepto de ruptura pactada tuvo un impacto más pronto. Alejandro Silva Bascuñán, abogado y dirigente señalaba lo siguiente: "Recuerda la lección brillante expresada por personeros de la nueva España que vinieron a decirnos que a pesar de las diferencias encontradas en España lograron acercamientos". Es decir, se valoró el consenso alcanzado en España para construir un nuevo orden constitucional entre distintas corrientes de pensamiento. En virtud de ellos, Bascuñán planteó la aplicación de la política consensual en el Chile de aquel momento -agobiado por la crisis- la cual permitiría construir un verdadero acuerdo patriótico nacional ${ }^{28}$. Edgardo Boeninger también compartía esta afirmación, y la planteaba al ser invitado a una sesión del Grupo. El dirigente DC era partidario de una salida institucional, ideas que expresó en numerosas ocasiones, como hemos comprobado en esta investigación. Afirmaba que la transición debía realizarse bajo cauces constitucionales, ya que de lo contrario, se corría el riesgo de llegar a una dictadura de otro signo ${ }^{29}$. De esta forma, la movilización social debía ser un complemento de la vía electoral. Sin embargo, señaló que los efectos de la protestas del 27 de mayo de 1984 podrían significar el riesgo de una polarización social, en que la clase media terminase apoyando a la dictadura.

Ahora bien, hacia mediados de la década de los ochenta, la influencia del proceso español en Chile ya no sólo se reduciría a una inspiración discursiva, sino que avanzaría hacia una influencia directa del mundo político ibérico en la realidad chilena. La llegada del PSOE al poder en 1982 marcó un nuevo tipo de acercamiento entre España y América Latina, caracterizado por un potenciamiento de las relaciones tanto económicas como políticas (Lasagna, 1991: 131-143). Ya en 1983, y con apenas siete meses en el gobierno,

\footnotetext{
${ }^{26}$ Acta reunión Comisión de Estudios Constitucionales, 5 de abril de 1984, p. 2 en Archivo Histórico Fundación Eduardo Frei Montalva. El resaltado es nuestro.

${ }^{27}$ El concepto "familias" hace referencia a los distintos grupos que conformaban el régimen franquista: monárquicos, falangistas, tecnócratas, etc.

${ }^{28}$ Acta reunión Comisión de Estudios Constitucionales, 27 de marzo de 1984, 2 en Archivo Histórico Fundación Eduardo Frei Montalva.

${ }^{29}$ Acta reunión Comisión de Estudios Constitucionales, 27 de marzo de 1984, 7 en Archivo Histórico Fundación Eduardo Frei Montalva.
} 
Felipe González realiza una gira por el continente, visitando México, Panamá, Venezuela, Colombia y Estados Unidos. Al explicar la razón para este viaje (que también incluyó la visita del Rey Juan Carlos a Brasil y Uruguay), González explicaba que Latinoamérica era considerada el "área natural” de España.

En este nuevo marco, el discurso de los DD.HH. y la democracia se transformó en un eje de la estrategia exterior española, siendo Chile uno de los países predilectos para su aplicación. La concretización de esta estrategia se reflejó en la visita de varios políticos españoles al Cono Sur para relatar la experiencia española y "exportar" las lecciones que esta habría dejado en los españoles. Según documentos desclasificados por EE.UU., doce embajadas europeas en Chile se coordinaron para elaborar una estrategia de apoyo hacia la oposición chilena, específicamente a aquellos sectores "democráticos", a los cuales vinculaban con la Alianza Democrática. Sin embargo, los documentos no mencionan aportes monetarios, sino más bien "acompañamiento para sostener la moral", aunque se enfatizaba en la necesidad de ser "discretos" a la hora de apoyar determinados partidos, pues una ligazón demasiado pública podría haberse considerado una intromisión extranjera, fomentando el discurso del régimen relativo a las conexiones internacionales de la oposición y el "marxismo"30.

Lo anterior finalmente se tradujo en una profundización de los lazos generados entre la oposición chilena y la sociedad española. De esta forma, en 1983 viajan a Chile dos políticos españoles de cierta relevancia: José María "Txiki” Benegas en junio y Fernando Álvarez de Miranda en octubre. El primero era el Secretario General del Partido Socialista Vasco, y en una entrevista realizada por Madlen Yopo, planteó que la transición española se desarrolló en un ámbito de consenso, incluso entre aquellos que habían sido "enemigos jurados" años atrás ${ }^{31}$. También enfatizó en la necesidad de integrar al PC chileno en las negociaciones llevadas a cabo por la $\mathrm{AD}$, pues estos representaban a parte importante del pueblo chileno, al igual que el PCE español ${ }^{32}$. Por su parte, Álvarez de Miranda era integrante de la Democracia Cristiana española, grupo escindido de la Unión de Centro Democrático (UCD) y asiduo visitante a nuestro país, pues ya había estado en 1978 y en 1982, con ocasión de la muerte de Eduardo Frei Montalva. Durante su estadía es entrevistado por la revista Hoy, donde refrenda su posición sobre la transición española y su enseñanza para los chilenos. Al ser consultado por la responsabilidad que le caben a los políticos en este proceso, planteó que:

Tiene que saber tener la suficiente serenidad y prudencia o instinto político para adivinar los momentos precisos para dar pasos oportunos, aceptando incluso la posibilidad de cambio si hubiera una oferta sincera de quienes ostentan el poder. Recuerdo el gesto

\footnotetext{
${ }^{30}$ Estas naciones eran Alemania Federal, Bélgica, Inglaterra, Francia, Italia, Portugal, Noruega, Luxemburgo, Irlanda, Dinamarca y Grecia. Para mayores detalles, revisar el documento Fm amembassy Santiago To secstate washdc inmediate 8678, subj: views of EC ambassadors in Santiago of the oposittion, october en http://foia.state.gov/Default.aspx

31 "Raíces para la democracia" Revista Análisis 60 (1983) 30-32.

32 "Raíces para la democracia" 32.
} 
generoso de las últimas cortes franquistas, las que, autodisolviéndose, convocaron a elecciones democráticas. Ese gesto fue aceptado por el pueblo y hoy tienen, por él, el reconocimiento de casi todos los españoles. ${ }^{33}$

Durante su estadía también dictó una charla en la sede de CIEPLAN, también rescatada en sus aspectos fundamentales por revista $\mathrm{Hoy}^{34}$. Su alocución se centró fundamentalmente en la necesidad de generar un pacto o consenso entre todos los sectores oposición y los grupos reformistas del propio régimen, utilizando para ello el ejemplo de España:

En lo que se refiere, reitero, a la búsqueda del consenso. Sin un acuerdo de todas las fuerzas políticas no es posible llegar a elecciones democráticas competitivas, que representen verdaderamente una opción de futuro. Esto es válido para cualquier régimen autoritario que esté evolucionando hacia pautas democráticas y un pacto de restauración democrática no puede ser celebrado por un solo partido, un solo sector social o un solo grupo económico: es una labor conjunta de toda la sociedad y en la que no puede quedar nadie marginado. (...) Porque la paz es anterior a cualquier planteamiento político, y la paz democrática significa ante todo y sobre todo dialogo, entendimiento y consenso.

Ambos extractos plantearon algunas máximas fundamentales para la izquierda socialista chilena durante estos años. Ante la división del socialismo en dos conglomerados (PS-Briones en la AD y PS-Almeyda en el MDP), aquellos donde la renovación penetró de forma más profunda, argumentaron que la discusión en Chile debía superar las diferencias producidos en el debate sobre el tipo de sociedad que debía construirse con posterioridad a la caída de la dictadura. En palabras de Ricardo Núñez, no se trataba de una disyuntiva entre "socialismo o dictadura, sino entre democracia y dictadura", por lo que luego de superada la práctica autoritaria, podrían las distintas fuerzas políticas confrontar sus visiones de sociedad $^{35}$.

Otra visita importante fue la realizada por Oscar Alzaga (presidente del Partido Demócrata Popular, PDP) y Juan Carlos Guerra Zunzunegui, vicepresidente del Senado español y también militante del PDP en 1985, con motivo del cincuentenario de la Democracia Cristiana. El PDP era un pequeño partido de orientación demócrata-cristiana (16 diputados y 12 senadores a la fecha), cuya alianza con el partido derechista Alianza Popular (AP) era observada con extrañeza en Chile. En esta visita, Alzaga se refirió a la aparente contradicción entre haber sido opositor a Franco, y luego conglomerarse con la AP, apoyando como candidato a las presidenciables de 1986 a Manuel Fraga, ex ministro franquista. Para él, este apoyo se basó en el "realismo" y en la necesidad de generar una

\footnotetext{
33 "No se pueden hacer remedos de transición", Revista Hoy 335 (1983) 19.

34 “Consenso, palabra mágica", Revista Hoy 337 (1983) 28-29.

${ }^{35}$ Esta expresión se encuentra en "Los socialistas y la Alianza”, Revista Análisis 64 (1986), 14.
} 
oferta "que tome lo mejor de la derecha democrática y el centro popular", con el objetivo de "hacerle frente al socialismo". Lo importante es que extrapoló esta situación a la realidad chilena, planteando que "no debe haber temor por parte de la DC chilena a buscar arreglos con los sectores democráticos de la derecha, incluso aunque estos apoyen a Pinochet". Si bien no se podían soslayar los "aspectos oscuros" de la dictadura, también había que tomar en cuenta la "realidad vigente" y buscar una salida constitucional hacia la democracia ${ }^{36}$.

Una forma más elaborada de relación directa entre Chile y España fue la organización de una serie de reuniones, congresos y seminarios donde se invitaba a destacadas personalidades europeas. La historiadora Encarnación Lemus (2001) ha pesquisado varios de ellos, entre los que se cuentan el "Seminario sobre la Transición Española" en el Instituto Hispano-chileno de Cultura en junio de 1983 y el Ciclo de Conferencias denominadas "España Hoy: su realidad cultural, social y política", con las intervenciones de políticos, académicos y artistas españoles, entre los cuales se encontraban Alberto Reig, Luis Suñen, Javier Bobillo y Fanny Rubio realizado en enero de 1984. Durante este año también visitó el país el destacado politólogo Ludolfo Paramio, quien brindó dos conferencias, una sobre sindicalismo en el local de VECTOR y otra sobre los "Desafíos del proceso democrático español" en el Instituto Hispánico Cultural ${ }^{37}$. En esta última Paramio desarrolló una especie de cuadro comparativo entre la transición española y las condiciones que, supuestamente, presentaba Chile en aquel año, las cuales habrían sido "casi idénticas" al caso español durante la segunda mitad de los setenta, especialmente en lo referido a la unidad opositora y el desgaste del régimen en su relación con la ciudadanía.

Mención aparte merece la realización de las jornadas "Consenso y transición: la experiencia de España", organizadas por la Fundación Eduardo Frei Montalva en 1986. Este encuentro resulta interesante, pues reunió a una importante cantidad de políticos chilenos de oposición con algunos de sus pares españoles, entre los que se encontraba Adolfo Suarez, junto a Oscar Alzaga (PDP) y Leopoldo Torres (PSOE). También resultó importante porque se produjo en el momento que se discutía el Acuerdo Nacional propuesto por el Cardenal Fresno y que representó la última oportunidad de la oposición para lograr acelerar el proceso de transición. Y por si esto fuese poco, durante este año España intensificó su estrategia internacional en contra del gobierno chileno al presentar ante la CEE una moción pidiendo sanciones condenatorias contra la violación de Derechos Humanos en Chile (Lasagna: 137) y acusándolo de espionaje contra su embajada ${ }^{38}$.

Lo anteriormente expresado hizo de esta actividad un encuentro de gran importancia dentro de la oposición chilena. La modalidad utilizada fue el de exposiciones acompañadas de comentarios. En las intervenciones de los políticos españoles cada exposición se

\footnotetext{
36 "Con paciencia y cálculo", Revista Hoy 431 (1985), 75.

37 "España: se fortalece la democracia", Fortín Mapocho, 309 (1984), 13.

${ }^{38}$ En agosto de 1986, el Canciller español Francisco Fernández Ordoñez, acusó a los servicios secretos de la dictadura de espionaje en contra de su embajada en Santiago, específicamente a su embajador Miguel Solano Aza. Según el gobierno español, los espías buscaban información respecto a la posición del gobierno de Felipe González y a los contactos entre la oposición chilena y diplomáticos españoles. Para mayor información, revisar: "España comprobó que hubo espionaje chileno”, Fortín Mapocho, 376 (1986), 7.
} 
complementó con comentarios de sus pares nacionales, de esta forma la ponencia de Suarez, titulada "El proceso político de la transición española", fue comentada por Ricardo Núñez (PS-Núñez) y Gabriel Valdés (DC). "Filosofía para el consenso para una democracia" de Alzaga, con los de Ricardo Navarrete (PR) y Julio Subercaseaux (P. Republicano) y, finalmente, "Consenso español: el acuerdo constitucional", por Leopoldo Torres, recibió los comentarios de Rene Abeliuk (Socialdemocracia) y Pedro Correa (Alianza de Centro). Junto con la presidencia de decisivos representantes de la plataforma de Acuerdo Nacional, el seminario contó también con la colaboración de la Alianza Democrática y la Comisión de Derechos Humanos. El diario opositor Fortín Mapocho le brindó gran importancia a la conferencia de Suarez, planteando que "su posición de tomar una legalidad para cambiarla y arribar a la democracia - lo que en el caso español fue plenamente exitoso y en un marco pacífico - parece haber dejado una importante influencia en parte de la oposición" 39 . Si bien entendía que esta experiencia podía ser positiva, había que entenderla con "gruesos matices", adaptándola a la realidad chilena.

Volviendo al seminario ${ }^{40}$ propiamente tal, la discusión giró alrededor de los temas que ya hemos descrito: la observación de la experiencia española como modelo a seguir, específicamente en sus dos ámbitos principales: el consenso democrático y la opción de la ruptura pactada. Una de las reflexiones más interesantes en este sentido la realizó Eduardo Frei Ruiz-Tagle, quien participó en el encuentro en su rol de experto en economía de la DC, pero sorprendió con un sesudo análisis de las lecciones que debía aprender Chile de su "madre patria". Primero, remarcó el tema del consenso entre los grupos de oposición y, agregó, la confluencia de los mismos con las "fuerzas que vienen a la democracia desde dentro del régimen autoritaria", aludiendo de forma explícita a la idea de una "ruptura pactada". Frei hizo referencia directamente a la necesidad de buscar un "pacto entre la oposición y las FF.AA”. Luego, declaró su preferencia por la utilización de la legalidad creada por la dictadura, en plena concordancia con los dichos de Aylwin, aduciendo además los casos contemporáneos de Filipinas y Brasil. Por último, el futuro presidente manifestó que otra enseñanza básica de la transición española había consistido en que hubiera "logrado unir al país en un camino de moderación, de justicia y sensatez".

En definitiva, la intervención de Frei resume de forma esquemática la posición de quienes, idealizando al modelo español, defendieron la postura de la ruptura pactada. Estas declaraciones venían acompañadas de mensajes tranquilizadores hacia los estamentos considerados como pilares del régimen militar: las FF.AA. y el empresariado, pidiendo al mismísimo Suarez que ahondase en la mejora que, supuestamente, estos grupos habrían encontrado en la democracia española. Con el mismo objetivo, Alzaga, planteó el principio de la rentabilidad, en el sentido de que, cuando el "precio" de la represión, supera al "precio" de la tolerancia, la estabilidad económica de la nación se ve afectada, generándose un caos institucional contrario al crecimiento económico.

El resto de las ponencias giraron alrededor de los temas ya descritos, como la reconciliación nacional, la estabilidad económica o la necesidad del consenso. Cuando se

\footnotetext{
39 “Febrero: el mes de las resoluciones” Fortín Mapocho, 382 (1987), 3.

${ }^{40}$ Las citas sobre este tópico se encuentran en Lemus (2001: 132-134)
} 
entraba en el debate sobre el alcance del consenso en España, se abordaba no sólo la aplicación que anteriormente hemos tratado -el converger la oposición hacia la unidad-, sino también, y más importante, la confluencia entre la oposición y sectores reformistas nacidos dentro del régimen. Eduardo Frei, Gabriel Valdés, Ricardo Navarrete y Pedro Correa repitieron la alternativa de búsqueda de un pacto con las FF.AA. Incluso Navarrete iba más lejos, al decir que este acercamiento debió haberse producido antes, pues:

... de la enseñanza española se deduce la necesidad de dirimir el conflicto que ha tenido entrampada a la oposición en una suerte de excesivo voluntarismo más que en una conducta práctica $\{\ldots\}$ hemos llegado tarde a la definición de materias que hubieran ayudado mucho a la oposición democrática y a la definición de un camino de mayor eficacia.

Por el contrario, Ricardo Núñez no lo creía posible, manifestando el peligro de que un acuerdo de esta índole pudiese derivar en una especie de "democracia tutelada" por los militares. Si bien manifestó su apoyo a la unidad de la oposición, incluso integrando a quienes habían optado por "todas las formas de lucha", pero al momento de negociar con el régimen, había que ser cuidadosos y evitar la legitimación de Pinochet a través de negociaciones que pudiesen ser considerados como "espurias" por las bases sociales de la oposición. Esta visión de Núñez demuestra que la adopción de la táctica de la ruptura pactada fue un proceso progresivo dentro de los partidos que conformaban la $\mathrm{AD}^{41}$.

\section{Conclusiones}

A finales de 1987 ya estaba desechada la opción del Acuerdo Nacional, y varios dirigentes comenzaron a resignarse a cumplir con los plazos establecidos por la Constitución de 1980. Consideramos que la formación de la Concertación de Partidos por el NO significó la victoria definitiva de la opción de la ruptura pactada dentro de la oposición. También cimentó la exclusión definitiva de aquellos grupos que desde comienzos de la década se declararon seguidores de la movilización social y la vía insurreccional (o la ruptura democrática, visión matizada de esta postura).

Ambas opciones fueron el resultado de una disputa interna, donde acción y teoría se conjugaban en una relación dialéctica. Ciertas coyunturas favorecían una u otra opción como la masividad de las protestas o los resultados de las negociaciones con la dictadura- y al mismo tiempo, las elucubraciones teóricas determinaban el accionar de los sujetos. De esta forma, la utilización del imaginario de la transición española cumplió la función de alimentar esta disputa, brindándole legitimidad a la formación de una cultura política de

\footnotetext{
${ }^{41}$ Núñez desarrolla con mayor extensión este análisis en dos columnas de opinión: "Ochentaynuevismo", Revista Análisis 112 (1985) 2 y “Ochentaynuevismo con riendas sueltas”, Revista Análisis 115 (1985) 4-6.
} 
transición, la cual terminó por imponerse dentro de los sectores que finalmente le dieron forma a la transición chilena.

Pudimos observar como el grado de influencia del "modelo español" en Chile aumentó de forma progresiva. Cuando la oposición recién comenzaba un proceso de agrupamiento alrededor del plebiscito de 1980, la transición española era utilizada como forma de legitimar teóricamente la necesidad de una alianza entre el centro y la izquierda, rescatando la experiencia del PSOE y la Platajunta, algo que era anómalo en la historia democrática chilena. Luego de cristalizado este proceso, la formación de alianzas más o menos estables cambio el foco de la discusión, centrándose en la estrategia que debía utilizarse para acelerar el camino a la democracia. Mientras en el MDP, el liderazgo del PC imponía cierto camino de forma clara, en la Alianza Democrática comenzó una disputa que se alargó por casi cuatro años. Ruptura democrática o pactada era el binomio en que se fundamentaba el debate. En este contexto, la utilización del imaginario de la transición española y la influencia directa del mundo político ibérico jugó un papel relevante en la opción por la ruptura pactada, posición que finalmente se impuso hacia 1987.

Creemos que el análisis del proceso transicional chileno desde una perspectiva historiográfica resulta una tarea ineludible en la actualidad. Esto debido no sólo a la escasa producción académica sobre el periodo, sino que también por ser un proceso esencial para comprender nuestro presente. Entre aquellos aspectos que se encuentran aún oscurecidos sobre la transición chilena, su dimensión internacional cobra gran relevancia, pues también permite localizar a Chile dentro del mapa global a finales de la Guerra Fría, confirmando la necesidad de observar los procesos históricos sin las restricciones de lo "nacional" En el caso de la transición chilena, resulta ineludible asumir la existencia de procesos acaecidos fuera de las fronteras del Estado chileno (como la renovación socialista y la solidaridad internacional), los cuales generaron circulaciones de saberes y prácticas relativos a las formas que debía adquirir un eventual tránsito a la democracia.

Claramente el caso español no agota las posibilidades de realización de una historia transnacional de la transición chilena. Temáticas relacionadas a la influencia estadounidense (tanto en la oposición como en la propia dictadura), el papel jugado por el resto de los países latinoamericanos o el imaginario de otros acontecimientos internacionales en la oposición chilena -como la revolución iraní de 1979, las guerras civiles en América Central u otras transiciones cercanas (como la brasileña o argentina)- se encuentra aún casi inexploradas por la historiografía chilena e internacional.

\section{Obras citadas}

\section{$\underline{\text { Fuentes }}$}

Archivo Histórico Fundación Eduardo Frei Montalva 
Acta reunión Comisión de Estudios Constitucionales, 27 de marzo de 1984, 2.

Acta reunión Comisión de Estudios Constitucionales, 5 de abril de 1984, p. 2.

\section{$\underline{\text { Diario Fortín Mapocho }}$}

“España: se fortalece la democracia”, 309 (1984), 13.

"Me encontré con la Patria", 297 (1984), 6.

"España comprobó que hubo espionaje chileno", 376 (1986), 7.

"Febrero: el mes de las resoluciones", 382 (1987), 3.

\section{$\underline{\text { Revista APSI }}$}

"Pacto de la Moncloa para Chile”, 68 (1980) 2.

“Cortes españolas: la democracia no quiere a Suarez”, 76 (1980). 17-18.

\section{$\underline{\text { Revista Hoy }}$}

“No se pueden hacer remedos de transición”, 335 (1983) 19.

“Consenso, palabra mágica”, 337 (1983) 28-29.

“Con paciencia y cálculo”, 431 (1985), 75.

\section{$\underline{\text { Revista Análisis }}$}

“España: romper con la nostalgia”, 53 (1983) 33-35.

“Los socialistas y la Alianza”, 64 (1983) 14.

“Ochentaynuevismo”, 112 (1985) 2.

“Ochentaynuevismo con riendas sueltas”, 115 (1985) 4-6. 


\section{Bibliografía}

- Alcántara Sáez, Manuel. "Las transiciones a la democracia en España, América Latina y Europa Oriental. Elementos de aproximación a un estudio comparativo", Revista del Centro de Estudios Constitucionales 11 (1992).

- Álvarez, Rolando. Desde las sombras, una historia de la clandestinidad comunista (1973-1980) Santiago: LOM ediciones, 2003.

- Arancibia, Patricia, Góngora, Álvaro y Fernández, Joaquín. Ricardo Núñez: trayectoria de un socialista de nuestro tiempo. Santiago: Ediciones Finis TerraeCIDOC, 2013.

- Araya, Rodrigo. Del combate a la dictadura a la preservación de la democracia. Movimiento sindical y políticas de concertación social. Los casos de Chile y España (1975-1994). Tesis para optar al grado de Doctor en Historia Contemporánea, Universidad Autónoma de Barcelona, 2012.

- Arrate, Jorge y Rojas, Eduardo. Memoria de la Izquierda chilena, dos volúmenes. Santiago: Ediciones B Chile S.A, 2003.

- Aylwin, Patricio. Una salida político-institucional para Chile: exposiciones y debate del seminario Santiago: Instituto Chileno de Estudios Humanísticos, 1985.

- Camacho, Fernando. "Las relaciones entre Chile y Suecia durante el primer gobierno de Olof Palme, 1969-1976”, Iberoamericana 25 (2007)

- Cañas Kirby, Enrique. Proceso político en Chile: 1973-1990. Santiago: Ed. Andrés Bello, 1997.

- De la Guardia, Carmen y Pan-Montojo, Juan. "Reflexiones sobre una historia transnacional”, Studia histórica. Historia contemporánea 16 (1998).

- Durán, Carlos. "Notas breves sobre la crisis y la renovación de la Izquierda Chilena" Revista Investigación y Crítica 6 (2001).

- Fermandois, Joaquín. "La internacionalización de la historia internacional" Ampliando Miradas. Chile y su historia en un tiempo global, eds. Fernando Purcell y Alfredo Riquelme. Santiago: RIL Editores, 2009. 
- García Gutiérrez, Cristina Luz. "La imagen de España en el cono sur: ¿madre patria o pueblo hermano? (1973-2013)", inédito.

- García Gutiérrez, Cristina Luz. "Españoles desaparecidos en Chile: una perspectiva transnacional de investigación", Ponencia presentada en el $9^{\circ}$ Encuentro Internacional de ANPHLAC, Universidades Federal de Goiás, 2010.

- Goicovic, Igor. "La transición política en Chile. Especificidades nacionales y puntos de referencia con el caso español (1988-1994) “, Claves internacionales en la transición española, Oscar Martín García y Manuel Ortiz Heras (coords.). Madrid: Libros de la Catarata, 2010.

- Goicovic, Igor. "La refundación del capitalismo y la transición a la democracia en Chile (1973-2004)", Historia Actual 10 (2006).

- González, Damián. El franquismo y la transición en España: desmitificación y reconstrucción de la memoria de una época. Madrid: Los Libros de la Catarata, 2008.

- Huneeus, Carlos. El régimen de Pinochet. Santiago: Editorial Sudamericana, 2005.

- Lasagna Barrena, Marcelo. "Las relaciones chileno-españolas: 1882-1989. Del primer gobierno socialista español al ocaso de la dictadura chilena", Afers Internationals 22 (1991)

- Lemus, Encarnación. En Hamelin...: la transición española más allá de la frontera. Madrid: Septem Ediciones, 2001.

- Mir García, Jordi. "Salir de los márgenes sin cambiar las ideas. Pensamiento radical, contracultural y libertario en la transición española", Ayer, 1.81 (2011).

- Moulian, Tomas. Chile actual: anatomía de un mito. Santiago: LOM ediciones, 1997.

- Moyano, Cristina. "Los líderes de la izquierda. Configuración de las elites en el imaginario político chileno dictatorial y el rol de las revistas políticas de oposición, 1973-1989”, Bicentenario. Revista de Historia de Chile y América 8.1 (2009). 
- Moyano, Cristina. "El golpe de Estado y la erosión de los mapas cognitivos. Renovación socialista y efectos en la postdictadura", A 40 años del golpe de Estado en Chile: continuidades y rupturas en la historia reciente: Actores, políticas y educación, ed. Cristina Moyano. Santiago: Editorial de la Universidad de Santiago, 2013.

- Ortega Frei, Eugenio. Historia de una alianza política: el partido Socialista de Chile y el partido Demócrata Cristiano: 1973-1988. Santiago: Biblioteca Nacional de Chile, 2005.

- Ortiz Heras, Manuel. "Historiografía de la transición”, La transición a la democracia en España. Historia y fuentes documentales. VI Jornadas de Castilla-La Mancha sobre investigación en archivos. Guadalajara. Anabad Castilla-La Mancha: 2004.

- Sánchez Recio, Glicerio. "Familias políticas, estructuras del poder, instituciones del régimen”, Revista Ayer 1.15 (1994).

- Sánchez-Soler, Mariano. La transición sangrienta. Una historia violenta del proceso democrático español (1975-1983). Madrid: Península ediciones, 2010.

- Saz, Ismael. Y la sociedad marcó el camino. O sobre el triunfo de la democracia en España (1969-1978). España: Siglo XXI, 2011.

- Pedrosa, Fernando. "La influencia externa en las transiciones de la "tercera ola" en América Latina. Debates, definiciones y propuestas teóricas”, PolHis 12 (2013).

- Pedrosa, Fernando. "Partidos políticos y acciones trasnacionales: El Comité para América Latina y el Caribe de la Internacional Socialista (1976-1983)", Revista Izquierdas 22 (2015).

- Portales, Felipe. Chile. Una democracia tutelada. Santiago: Editorial Sudamericana, 2000.

- Rodríguez, Álvaro. La legitimación política del franquismo: de la II Republica a la instauración de la democracia en España. Madrid: Editorial CSED, 2014.

- Ulianova, Olga. "Relaciones internacionales y redefiniciones en el socialismo chileno, 1973-1979”, Revista Izquierdas 4 (2009). 
- Yocelevsky, Ricardo. Chile: partidos políticos, democracia y dictadura 1970-1993. México: Fondo de Cultura Económica, 2002.

- Zaldívar, Andrés. La transición inconclusa. Santiago: Editorial Los Andes, 1995.

Recibido: 2 abril 2015 Aprobado: 4 junio 2015 